\title{
Response-independent reinforcement in the crow: Failure to obtain autoshaping or positive automaintenance
}

\author{
ROBERT W. POWELL, WILLIAM KELLY, and DAVID SANTISTEBAN \\ University of South Florida, Tampa, Florida 33620
}

\begin{abstract}
Only 3 of 17 crows developed appreciable responding under autoshaping procedures similar to those which reliably engender responding in pigeons. This occurred despite variations in the following conditions: species of crow (fish or common), fixed vs. variable intertrial interval, duration of intertrial interval, type of reinforcer, level of test chamber illumination, and the presence or absence of a response-reinforcer dependency. Ten of the crows were subsequently exposed to shaping through the method of successive approximation, and all were conditioned to keypeck reliably within a relatively brief period. When three of these crows were again exposed to keylight-food pairings (automaintenance), their responding attenuated over time to near the zero level. An explanation of the behavioral differences between the crows studied here and pigeons studied under similar conditions is offered, based primarily upon differences in the feeding behavior of the two species in their natural environments.
\end{abstract}

A number of recent experiments have shown that pigeons develop keypecking when exposed to repeated keylight-food pairings, even though there is no contingency between the response and the reinforcer (Brown \& Jenkins, 1968; Gamzu \& Williams, 1971; 1973). This phenomenon is called autoshaping. It has been demonstrated convincingly that pecking is generated by autoshaping procedures only when an intermittently presented keylight is differentially associated with food, i.e., when the food is presented alone (Gamzu \& Williams, 1973), or the stimulus and the food are separated temporarlly (Bilbrey \& Winokur, 1973), pecking does not occur.

A number of experiments which have purported to show autoshaping in other species included the contingency that each response in the presence of the stimulus immediately produced food (Sidman \& Fletcher, 1968; Smith, Borgen, Davis, \& Pace, 1971; Squier, 1969). Several experimenters have pointed out that the presence of such a response-reinforcer dependency makes it virtually impossible to assess the role of the stimulus-reinforcer dependency in the acquisition and maintenance of responding under autoshaping (Gamzu \& Schwam, 1974; Likely, 1974).

Psychologists have begun to pay increasing attention to biological or genetic constraints upon learning (Bolles, 1970; Seligman, 1970; Seligman \& Hager, 1972). For example, Seligman (1970) argues that pigeons are genetically prepared to associate pecking a lighted key with food; consequently they rather quickly develop pecking under the autoshaping procedure. The extent to which other species are similarly prepared is an empirical question. It is axiomatic that the theoretical significance of autoshaping depends upon its power and generality, yet little research has been aimed at these questions. The present experiments addressed these questions by studying crows under autoshaping and automaintenance procedures. We have previously shown that crows can be shaped to keypeck for food (Powell, 1973) and that their response patterns are quite similar to pigeons under basic schedules of reinforcement (Powell, 1972). The crow seems to be a particularly important species for study, as some ornithologists believe that crows and other corvids represent the most advanced form of avian evolution (Thomson, 1964).

\section{EXPERIMENT I}

\section{Method}

Subjects. The subjects were nine adult common crows (Corvus brachyrhynchos) which had been obtained from a commerical supplier in Wisconsin. The birds had been taken from their nests just prior to fledging and were experimentally naive. All birds were maintained at between $80 \%$ and $85 \%$ of their normal weights during the experiment and were housed in individual cages with water and grit freely available.

Apparatus. A three-key operant conditioning chamber for large birds (Lehigh Valley Electronics Model 132-06) was used, but only the center response key was functional. The other two keys were covered. The response key was located $30.5 \mathrm{~cm}$ above the floor, while the opening to the foodtray was $16.0 \mathrm{~cm}$ below the key. The houselight was mounted above the key in a housing which directed the light toward the ceiling.

Procedure. All birds were first given automatic magazine training in which the food hopper was presented for $5 \mathrm{sec}$ at 30-sec intervals until they reliably approached and ate from the hopper when it was presented. This was accomplished for each bird within one 30-min session. Each crow was then exposed to pairings of the keylight, which was transilluminated from the rear with white light, followed by a brief presentation of the foodtray at the offset of the light. The illumination of the keylight constituted a trial. The keylight was dark between trials. Keypecks during the trial, or between trials, had no schedule 
Table 1

The Experimental Parameters and the Mean and Range of Responses, Both Within and Between Trials, for Each Subject

\begin{tabular}{|c|c|c|c|c|c|c|c|c|}
\hline \multirow[b]{2}{*}{ Subjects } & \multirow{2}{*}{$\begin{array}{c}\text { Ses- } \\
\text { sions }\end{array}$} & \multirow{2}{*}{$\begin{array}{c}\text { ITI } \\
(\mathrm{sec})\end{array}$} & \multirow{2}{*}{$\begin{array}{c}\mathrm{RT} \\
(\mathrm{sec})\end{array}$} & \multirow[b]{2}{*}{ Reinforcer } & \multicolumn{2}{|c|}{ Within-Trial Responses } & \multicolumn{2}{|c|}{ Intertrial Responses } \\
\hline & & & & & Mean & Range & Mean & Range \\
\hline \multirow[t]{2}{*}{$\mathrm{C} 1$} & 5 & $20(\mathrm{~V})$ & 5.0 & Top Choice & 0 & 0 & 0 & 0 \\
\hline & 4 & $20(\mathrm{~V})$ & 5.0 & Ken-L-Biskit & 0 & 0 & 0 & 0 \\
\hline $\mathrm{C} 2$ & 5 & $20(V)$ & 5.0 & Top Choice & 2.0 & $1-3$ & 2.4 & $0-7$ \\
\hline $\mathrm{C} 3$ & 5 & $20(V)$ & 5.0 & Top Choice & 2.2 & $0-10$ & 0 & 0 \\
\hline \multirow[t]{2}{*}{$\mathrm{C} 4$} & 5 & $20(\mathrm{~V})$ & 5.0 & Top Choice & 0 & 0 & 0 & 0 \\
\hline & 4 & $20(V)$ & 5.0 & Ken-L-Biskit & .4 & $0-1$ & 0 & 0 \\
\hline \multirow[t]{2}{*}{$\mathrm{C} 16$} & 5 & $20(V)$ & 5.0 & Top Choice & .4 & $0-1$ & .4 & $0-2$ \\
\hline & 5 & $20(V)$ & 5.0 & Ken-L-Biskit & 10.8 & $1-30$ & 35.0 & $0-95$ \\
\hline $\mathrm{C} 13$ & 5 & $60(\mathrm{~F})$ & 4.0 & Mealworms & 0 & 0 & 0 & 0 \\
\hline $\mathrm{C} 14$ & 13 & $60(\mathrm{~F})$ & 4.0 & Mealworms & 35.8 & $1-74$ & 8.7 & $0-34$ \\
\hline $\mathrm{C} 17$ & 5 & $60(\mathrm{~F})$ & 4.0 & Mealworms & 0 & 0 & .8 & $0-2$ \\
\hline $\mathrm{C} 18$ & 5 & $60(\mathrm{~F})$ & 4.0 & Mealworms & .2 & $0-1$ & 1.4 & $0-7$ \\
\hline
\end{tabular}

Note $-R T=$ reinforcement time, $V=$ variable and $F=$ fixed intertrial interval.

consequences. This is called a fixed time trial (FTT). For four of the crows, the intertrial interval (ITI) was fixed, and trial duration was $8.0 \mathrm{sec}$, while for the remaining birds, it varied; and the trial duration was $6.0 \mathrm{sec}$. Intertrial intervals ranged from 2 to $60 \mathrm{sec}$ under the variable procedure. The session times were $100 \mathrm{~min}$ and $40 \mathrm{~min}$ for the fixed and variable ITIs, respectively. The reinforcers which were employed included live meal worms, Top Choice, which is a processed meat substitute dog food, and Ken-L-Biskit, a dried dog food. These have all been shown to be effective reinforcers for crows, with meal worms the most effective and Ken-L-Biskit the least effective of those used here. The experimental parameters employed with each subject are shown in Table 1.

\section{Results}

The data for all subjects, which are summarized in Table 1, shows that only two of the nine crows developed appreciable responding under autoshaping. Responding for Crow 16 increased markedly when the reinforcer was changed from Top Choice to Ken-LBiskit, but most pecks were between trials. Responding for this bird rapidly attenuated to near the zero level, however. Crow 14 made most of its responses within trials and, while there was some attenuation of responding over days, the decline was much less dramatic than for Crow 16.

The total number of trials to which each bird was exposed ranged from approximately 390 for Crows 2 and 3 to 1,500 for Crow 14 .

All of the crows reliably ate the food when it was presented, as evidenced by substantial within-session weight gains.

\section{EXPERIMENT II}

This experiment was conducted to see how well responding in crows would be maintained through stimulus-reinforcer pairings, once reliable keypecking had been established through a shaping procedure. This could be referred to as a study of positive automaintenance.

\section{Method}

Subjects and apparatus. Crows 1, 4, and 16 from Experiment I were used. The deprivation conditions and apparatus were the same.

Procedure. Since these three crows had either responded very little under autoshaping (C 1, C 4), or responding had declined to zero in the last autoshaping session (C 16), each was shaped to keypeck through the method of successive approximation. Shaping continued during daily $30-\mathrm{min}$ sessions until the animal reliably pecked the key, and training continued for two additional 30-min sessions under a continuous reinforcement schedule (CRF). The response key was continuously transilluminated with white light during shaping and CRF training sessions. The crows were then exposed to the same fixed time trial procedure as under autoshaping, for a total of 20 sessions. The sessions were $30 \mathrm{~min}$ in duration, with $6.0-\mathrm{sec}$ trials, a $20-\mathrm{sec}$ variable ITI, and $3.0-\mathrm{sec}$ reinforcement time. Intertrial intervals ranged from 10.0 to $100.0 \mathrm{sec}$, and there were 62 trials per session on the average. Top Choice was the reinforcer.

\section{Results}

The crows required eight (C 1), three (C 4), and one (C 16) shaping sessions in order to acquire keypecking. The mean number of responses and reinforcements over the two sessions of CRF training were 111,60 , and 53 for Crows 1,4 , and 16 , respectively. The results under the automaintenance procedure which are presented in Figure 1 show that little within-trial responding occurred. Except for the increase in responding by Crow 4 during the second block of sessions, each bird showed marked attenuation of responding to near the zero level by the end of this procedure. There was also little responding between trials, with the three birds making a total of only 10 (C 1), 37 (C 4), and 37 (C 16) intertrial responses over the 20 sessions. over the 20 sessions.

\section{EXPERIMENT III}

This experiment was conducted in order to broaden the scope of this research. Specifically, there were five dimensions along which the experimental conditions were extended: (1) A second crow species, the fish crow (Corvus ossifragus) was used. (2) A bright houselight was added, which served to localize the response key as a light source. Wasserman (1973) has shown that 
autoshaping readily takes place in a brightly lit test chamber but does not occur in a chamber without houselight illumination. (3) A longer variable ITI was used. A recent study (Terrace, Gibbon, Farrell, \& Baldock, 1975) has shown that the acquisition and maintenance of autoshaped responding is enhanced with increases in ITI duration, with trial time held constant. However, increases in terminal response rates were negligible at ITI values above $30 \mathrm{sec}$. (4) Fixed time trial (FTT) and variable time trial (VTT) procedures were compared. Under FTT, food is presented at the end of the trial whether or not a response occurs during the trial, whereas under VTT, food is presented immediately when a response occurs, or at the end of the trial when no response occurs. So FTT has only a stimulus-stimulus (S-S) contingency, whereas VTT has both S-S and response-stimulus (R-S) contingencies. Gamzu and Schwam (1974) reported that squirrel monkeys which developed keypressing under a VTT procedure showed marked attenuation of responding when switched to a FTT procedure. (5) Systematic observations of the crow's behavior during experimental sessions were made. Wessels (1974) has reported that orientation toward and approach to the key occur prior to keypecking in pigeons. It is possible that orientation and approach behaviors were conditioned in the earlier experiments here but were not measured.

\section{Method}

Subjects and apparatus. The subjects were eight adult fish crows (Corvus ossifragus) which had been trapped in the field as adults. They were maintained in captivity for 1 year prior to the experiment and were experimentally naive. All birds were maintained at between $80 \%$ and $85 \%$ of their normal weights during the experiment and were housed in individual cages with water and grit freely available. Fish crows are somewhat smaller than common crows, and the free-feeding weights of those studied here ranged from 281 to $329 \mathrm{~g}$. Most common crows weigh from 400 to $600 \mathrm{~g}$. The apparatus was the same as described earlier except that an auxiliary houselight was installed in the test chamber. This consisted of a $15-\mathrm{W} 115-\mathrm{V}$ ac incandescent bulb mounted in the ceiling of the test chamber adjacent to the wall opposite the response key. This light was on at all times during the experimental sessions.

Procedure. The birds were divided into two groups of four each as shown in Table 2, being exposed to either the FTT or VTT procedure (as described earlier). All birds were first given automatic magazine training for two sessions as described in Experiment I, and all reliably ate from the hopper during this training. The crows were then exposed to keylight-food pairings, with a trial duration of $6.0 \mathrm{sec}$ and a variable ITI which ranged from 9.0 to $75.0 \mathrm{sec}$ with a mean of $40.0 \mathrm{sec}$. Experimental sessions were $1 \mathrm{~h} / \mathrm{day}$, so there were approximately 78 food presentations per session. All birds were studied for 9 to 11 sessions. In addition, Crow $\mathbf{3 8}$ was switched from the VTT to the FTT procedure and was studied for four additional sessions. Following autoshaping, the crows which did not develop reliable responding underwent shaping as described in Experiment II. Top Choice was the reinforcer, and reinforcement time was $5.0 \mathrm{sec}$. Behavioral observations were made on all crows during eight or more of the autoshaping sessions, with particular attention to behavior exhibited when the keylight was illuminated.

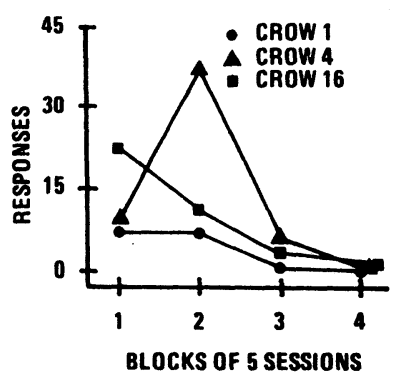

Figure 1. The mean number of responses per session for each crow under the automaintenance procedure averaged over blocks of five sessions.

\section{Results}

Of the eight crows, only Crow 38 ever made more than four within-trial responses during a session, as shown in Table 2. Responding between trials was negligible also, except for Crow 38. This bird showed a marked increase in responding during the sixth, seventh, and eighth sessions and then a slight decline during the last four sessions under the VTT procedure. Since there were approximately 78 trials per session, the percentage of trials with a response ranged from $38 \%$ to $53 \%$ from the 7 th through the 11 th session. When Crow 38 was switched to the FTT procedure, responding quickly declined to near the zero level.

This suggests that the response-reinforcer contingency included in the VTT procedure was the critical factor in the development of responding in this bird. Overall, the results again show that autoshaping is an ineffective procedure for engendering keypecking in crows.

Observation of the seven crows which showed negligible pecking during the autoshaping sessions failed to reveal any consistent behavioral pattern, either within or between trials. Most of the birds appeared to attend to or notice the keylight only infrequently. When it was observed, the usual response of the bird was to orient its body toward the food hopper. In none of these seven

Table 2

The Number of Sessions and the Mean and Range of Responses Per Session, Both Within and Between Trials, for Each Subject

\begin{tabular}{|c|c|c|c|c|c|}
\hline \multirow{2}{*}{$\begin{array}{l}\text { Sub- } \\
\text { jects }\end{array}$} & \multirow{2}{*}{$\begin{array}{l}\text { Ses- } \\
\text { sions }\end{array}$} & \multicolumn{2}{|c|}{$\begin{array}{c}\text { Within-Trial } \\
\text { Responses }\end{array}$} & \multicolumn{2}{|c|}{$\begin{array}{l}\text { Intertrial } \\
\text { Responses }\end{array}$} \\
\hline & & Mean & Range & Mean & Range \\
\hline \multicolumn{6}{|c|}{ Fixed Time Trials } \\
\hline $\mathrm{C} 20$ & 10 & .0 & 0 & .0 & 0 \\
\hline $\mathrm{C} 23$ & 9 & .0 & 0 & .0 & 0 \\
\hline $\mathrm{C} 24$ & 9 & .7 & $0-4$ & .4 & $0-3$ \\
\hline $\mathrm{C} 25$ & 11 & 1.2 & $0-3$ & .5 & $0-3$ \\
\hline \multicolumn{6}{|c|}{ Variable Time Trials } \\
\hline $\mathrm{C} 31$ & 11 & .5 & $0-3$ & .1 & $0-1$ \\
\hline $\mathrm{C} 35$ & 11 & .8 & $0-4$ & .0 & 0 \\
\hline C38 & 11 & 18.0 & $0-41$ & 4.9 & $0-22$ \\
\hline $\mathrm{C} 48$ & 11 & .0 & 0 & .4 & $0-4$ \\
\hline
\end{tabular}


crows was there incipient pecking during trials or any other bodily movement toward the response key.

When these seven crows were exposed to shaping through the method of successive approximation, they all developed reliable keypecking. Three of the birds started responding during the first 1 -h session, while Crow 48 was the slowest to respond, requiring six shaping sessions. The other birds required two, three, and four sessions to engender responding. Once

\section{GENERAL DISCUSSION}

The present experiments show that autoshaping is an ineffective procedure for engendering or maintaining keypecking in crows, so there would appear to be substantial differences between crows and pigeons in this respect. These findings would be unimpressive had it not been shown here and in earlier experiments that crows can be readily shaped to keypeck (Powell, 1973) and that they display response patterns quite similar to pigeons under fixed ratio, variable ratio, and variable interval schedules (Powell, 1972).

It has been shown that crows respond more successfully than pigeons under extended DRL schedules (differential reinforcement of low rate), achieving much higher rates of reinforcement (Powell, 1974). Crows also show more efficient behavior under fixed interval schedules, where they wait longer into the interval before responding and make fewer responses per reinforcement (Powell, 1972). So one possible explanation for the differences between crows here and pigeons in previous experiments is that crows are more sensitive to the contingencies of reinforcement which prevail. Several recent experiments with primates lend support to this notion, for these animals also showed much less responding under autoshaping procedures with only stimulus-reinforcer contingencies than has typically been found with pigeons (Gamzu \& Schwam, 1974; Likely, 1974).

While the concept of "preparedness" (Seligman, 1970) might be suggested as a basis for these differences, this concept possesses explanatory power only to the extent that it can be related to observable antecedent conditions. Such conditions would seem to exist in the feeding behavior of the two species. Crows are opportunistic, omnivorous feeders whose diet ranges from carrion to corn; but they have an apparent preference for meat and live insect larvae and little liking for grain (Powell, 1973). Domesticated pigeons (Columba livia), on the other hand, are almost exclusively grainiverous, feeding largely on small bits of grain and seeds. Thus, in their foraging behavior, pigeons are observed to peck almost constantly, whereas crows engage in little of this behavior as they search for larger food items. So it may be that pigeons are more likely to associate pecking with food because they engage in this behavior at a high rate when food is present in their natural habitat.

This type of explanation also gains support from the observation that the topography of the pecking response made by pigeons is a function of the kind of reinforcer which is presented during autoshaping (Jenkins \& Moore, 1973). Pigeons presented with grain as a reinforcer responded on the key with a grain-pecking movement, while birds presented water as a reinforœr responded with drinking-like movements. Similarly, Likely (1974) has reported that most of the responding to the autoshaped stimulus in rhesus monkeys resembled eating behavior, i.e., they contacted the response key with their mouths.

The present research appears to diminish somewhat the theoretical importance of autoshaping. It would seem that autoshaping is effective in promoting responding to the extent that the response being measured is associated with the food (reinforcer) presented, in the natural environment of the animal.
Consequently, only a limited number of response classes would appear to be conditionable through autoshaping. While it may be true that there are response classes in crows which can be autoshaped, one could similarly argue that responses other than pecking in pigeons probably cannot be autoshaped. However, these are questions which can be answered only through empirical study.

\section{REFERENCES}

Bilbrey, J.. \& Winokur, S. Controls for and constraints on autoshaping. Journal of the Experimental Analysis of Behavior. 1973, 20. 323-332.

Bolles, R. C. Species-specific defense reactions and avoidance learning. Psychological Review, 1970, 77, 32-48.

Bolles, R. C. Reinforcement, expectancy, and learning. Psychological Review, 1972, 79, 394-409.

Brown. P. L., \& Jenkins, H. M. Autoshaping of the pigeon's key-peck. Joumal of the Experimental Analysis of Behavior. 1968. 11. 1-8.

Gamzu, E. R., \& Schwam, E. Autoshaping and automaintenance of a key-press response in squirrel monkeys. Journal of the Experimental Analysis of Behavior, 1974, 21, 361-371.

Gamzu, E. R., \& Williams, D. R. Classical conditioning of a complex skeletal act. Science, 1971, 171, 923-925.

Gamzu, E. R., \& Williams, D. R. Associative factors underlying the pigeon's key pecking in autoshaping procedures. Journal of the Experimental Analysis of Behavior, 1973, 19, 225. 232.

JENKINS, H. M., \& Moore, B. R. The form of the autoshaped response with food or water reinforcers. Journal of the Experimental Analysis of Behavior, 1973, 20, 163-181.

Likely, D: G. Autoshaping in the rhesus monkey. Animal Learning \& Behavior, 1974, 2, 203-206.

Powell, R. W. Responding under basic schedules of reinforcement in the crow. Joumal of Comparative and Physiological Psychology, 1972. 79. 156-164.

Powell. R. W. Operant responding in the common crow (Corvus brachyrhynchos). Bulletin of the Psychonomic Society. 1973. 1. 401-403.

PowelL. R. W. Comparison of DRL responding in pigeons and crows. Journal of Comparative and Physiological Psychology, 1974. 86. $736-746$.

Seligman. M. E. P. On the generality of laws of learning. Psychological Review, 1970, 77, 406-418.

Seligman, M. E. P., \& Hager, J. L. Biological boundaries of learning. New York: Appleton-Century-Crofts. 1972.

Sidman. M.. \& Fletcher. F. G. A demonstration of autoshaping with monkeys. Journal of the Experimental Analysis of Behavior. 1968. 11. 307-309.

Smith. S. G.. Borgen. L. A., Davis, W. M., \& Pace, H. B. Automatic magazine and bar press training in the rat. Journal of the Experimental Analysis of Behavior. 1971, 15, 197-198.

Souier. . H. Autoshaping key responses with fish. Psychonomic Science, 1909, 17, 177-178.

Terrace, H. S., Gibbon, J., Farrell, L., \& Baldock, M. D. Temporal factors influencing the acquisition and maintenance of an autoshaped keypeck. Animal Learning \& Behavior, 1975, 3, 37.42.

Thomson, A. L. (Ed.) A new dictionary of birds. New York: McGraw-Hill, 1964.

Wasserman, E. A. The effect of redundant contextual stimuli on autoshaping the pigeon's keypeck. Bulletin of the Psychonomic Society. 1973. 1. 198-206.

WESSELS. M. G. The effects of reinforcement upon the prepecking behaviors of pigeons in the autoshaping experiment. Journal of the Experimental Analysis of Behavior. 1974. 21. 125-144.

(Received for publication June 9, 1975.) 